\title{
Application of exponential functions in weighted residuals method in structural mechanics. Part 3: infinite cylindrical shell under concentrated force
}

\author{
I.V. Orynyak ${ }^{1} \bullet$ Yu.P. Bai $^{1} \bullet$ A. V. Hryhorenko ${ }^{1}$
}

Received: 12 March 2021 / Accepted: 25 October 2021

\begin{abstract}
Solution for cylindrical shell under concentrated force is a fundamental problem which allow to consider many other cases of loading and geometries. Existing solutions were based on simplified assumptions, and the ranges of accuracy of them still remains unknown. The common idea is the expansion of them into Fourier series with respect to circumferential coordinate. This reduces the problem to 8th order even differential equation as to axial coordinate. Yet the finding of relevant 8 eigenfunctions and exact relation of 8 constant of integrations with boundary conditions are still beyond the possibilities of analytical treatment. In this paper we apply the decaying exponential functions in Galerkin-like version of weighted residual method to above-mentioned $8^{\text {th }}$ order equation. So, we construct the sets of basic functions each to satisfy boundary conditions as well as axial and circumferential equilibrium equations. The latter gives interdependencies between the coefficients of circumferential and axial displacements with the radial ones. As to radial equilibrium, it is satisfied only approximately by minimizations of residuals. In similar way we developed technique for application of Navier like version of WRM. The results and peculiarities of WRM application are discussed in details for cos $2 \varphi$ concentrated loading, which methodologically is the most complicated case, because it embraces the longest distance over the cylinder. The solution for it clearly exhibits two types of behaviors - long-wave and short-wave ones, the analytical technique of treatment of them was developed by first author elsewhere, and here was successfully compared. This example demonstrates the superior accuracy of two semi analytical WRM methods. It was shown that Navier method while being simpler in realization still requires much more (at least by two orders) terms than exponential functions.
\end{abstract}

Keywords: infinite cylindrical shell; concentrated radial force; Galerkin method; Navier method; accuracy, number of terms; short and long solutions.

\section{Introduction}

The distribution of deformations in elastic infinite cylindrical shell under concentrated radial force is a classical problem which potentially establish the basis for solving shells under different boundary conditions, loadings, and material properties. In spite of classical character of the problem, it is relatively scarcely described in literature and almost not presented in handbooks on the theory of shells. The starting point in all existing analysis is expansion of all unknown parameters into Fourier series $(\cos n \varphi, \sin n \varphi)$ as to circumferential coordinate $\varphi$. This reduces the problem

$$
\begin{aligned}
& \text { I.V. Orynyak } \\
& \text { orynyak.iv@gmail.com } \\
& { }^{1} \text { Igor Sikorsky Kyiv Polytechnic Institute, Kyiv, Ukraine }
\end{aligned}
$$

into $8^{\text {th }}$ order even differential equation with respect to axial coordinate. Classical, most natural way of solution is derivation of 8 eigenfunctions with 8 unknown coefficients which should be related with boundary conditions [1]. But a very complicated form of eigenfunctions, interrelations of their derivatives with different physical and geometrical parameters prevent the practical realization of this approach.

Historically the first was the work of Yuan [2] where two equal and opposite forces were considered. The governing $8^{\text {th }}$ order equation was initially simplified by omitting some terms and representing the looking for function as Fourier integral. The solution of simplified equation was presented in analytical form only for radial displacement. A little later Morley [3] slightly modernized characteristic equation which still allowed to get treatable eigenfunctions. Later on, these and similar results were generalized in the monograph of Lukasiewicz [4]. 
More correct and simpler approach was suggested in work [5] where the expansion in Fourier series was applied in axial direction as well, and this unnecessitated the simplification of governing equations. This method was applied by author and other investigators [6] to cylinders of finite length at specific boundary conditions. Yet it was never applied to cylindrical shell of infinite length, and this will constitute some novelty of present work.

A new family of solution became available with elaboration by Vlasov [7] of so-called semi-membrane theory of shells, which actually reduced the $8^{\text {th }}$ order task to $4^{\text {th }}$ order one. Its specific feature was assumption that solution change more quickly in circumferential direction than in axial one. Theory of Vlasov became a very popular one, and several its modifications were applied to the problem of interest $[8,9]$. Yet these papers were aimed only at derivation of the maximal deflection of the point of force application and their relative accuracies can be explained by overwhelming contribution of terms at smaller number of in expansion as to circumferential coordinate. The detailed review of these works was given in work [10].

The fact that Vlasov's solution is not self-sufficient and needs to be supplemented by accompanied 4th order problem was firstly elaborated by Calladine [11]. He even coined the more relevant term for Vlasov-like solutions long wave solution, in contrast to supplementary solution - short wave solution. Lately we used for brevity the terms "long" and "short" solutions [12, 13] and modified them. The latter approach was applied by us for more detailed analysis of action of one or two radial forces and results were successfully compared with FEA results [14].

The goal of present work consists in application of weighted residual method with employments of intentionally constructed sets of exponential functions which satisfy to required boundary conditions. As in paper [15] we also will elaborate and use for results verification the Navier method, which also can be considered as WRM application for a specific task. For particular case of we will derive and compare the complete analytical solution based on notions of short and long solution. Furthermore, the experience gained at preparation of work [15] will be used thoughtfully this paper.

\section{Problem statement and main equations}

For considered infinite shell Fig. 1 depicts all coordinates (angular $\varphi$, axial $x$ and radial $r$ ) and their positive directions; displacements in corresponding directions $(v, u, w)$; membrane forces $N_{x}, N_{\varphi}$, shear force $L$, transverse forces $Q_{x}$ and $Q_{\varphi}$; bending moments $M_{x}, M_{\varphi}$ and $M_{x \varphi}$.

We use the following geometrical and equilibrium equations [14]:

$$
\begin{gathered}
\frac{\partial N_{x}}{\partial x}+\frac{\partial L}{R \partial \varphi}=0, \quad \frac{\partial N_{\varphi}}{R \partial \varphi}+\frac{\partial L}{\partial x}+\frac{Q_{\varphi}}{R}=0 \\
\frac{\partial Q_{x}}{\partial x}+\frac{\partial Q_{\varphi}}{R \partial \varphi}-\frac{N_{\varphi}}{R}=0, \\
Q_{x}=\frac{\partial M_{x}}{\partial x}+\frac{\partial M_{x \varphi}}{R \partial \varphi}, \quad Q_{\varphi}=\frac{\partial M_{\varphi}}{R \partial \varphi}+\frac{\partial M_{x \varphi}}{\partial x}
\end{gathered}
$$

The above inner forces are related with deformations (membrane $\varepsilon, \gamma$ and bending $\chi$ strains) by physical equations:

$$
\begin{gathered}
N_{x}=-H\left(\varepsilon_{x}+\mu \varepsilon_{\varphi}\right), \quad N_{\varphi}=-H\left(\varepsilon_{\varphi}+\mu \varepsilon_{x}\right) \\
M_{x}=-H \delta\left(\chi_{x}+\mu \chi_{\varphi}\right), \quad \varepsilon_{\varphi \varphi}=-H \delta\left(\chi_{\varphi}+\mu \chi_{x}\right)
\end{gathered}
$$

Fig. 1. Directions of geometrical and force parameters: (a) 3D view of element; $(b)$ plane $(\varphi, r)$, (c) plane $(x, r)$

Here the usual designations are used: $H=E h /\left(1-\mu^{2}\right)$, $G=E / 2(1+\mu), \delta=h^{2} / 12, \mu$ is Poisson's ratio.

The third set of equations is the geometrical one, which relates the displacements with strains:

$$
\begin{gathered}
\varepsilon_{x}=\frac{\partial u}{\partial x}, \quad \varepsilon_{\varphi}=\frac{1}{R} \frac{\partial v}{\partial \varphi}+\frac{w}{R}, \quad \varepsilon_{x \varphi}=\frac{1}{R} \frac{\partial u}{\partial \varphi}+\frac{\partial v}{\partial x}, \\
\gamma_{x}=-\frac{\partial w}{\partial x}, \quad \gamma_{\varphi}=-\frac{\partial w}{R \partial \varphi}+\frac{v}{R} .
\end{gathered}
$$

Bending strains also depend on displacements. Their usual expressions are given as corresponding derivatives of angles of rotation $\gamma_{\varphi}$ and $\gamma_{x}$ [11]. But strains (3a) depend 
on variable radius and gives the contribution to bending strains too [14]. Eventually we will use the following modified expressions for them:

$$
\begin{gathered}
\chi_{x}=-\frac{\partial^{2} w}{\partial x^{2}}, \\
\chi_{\varphi}=\frac{\partial v}{R^{2} \partial \varphi}-\frac{\partial^{2} w}{R^{2} \partial \varphi^{2}}-\frac{\varepsilon_{\varphi}}{R}=-\frac{\partial^{2} w}{R^{2} \partial \varphi^{2}}-\frac{w}{R^{2}} \\
\chi_{x \varphi}=\frac{\partial v}{R \partial x}-\frac{2 \partial^{2} w}{R \partial \varphi \partial x}-\frac{\varepsilon_{x \varphi}}{R}=-\frac{2 \partial^{2} w}{R \partial \varphi \partial x}-\frac{1}{R^{2}} \frac{\partial u}{\partial \varphi} .
\end{gathered}
$$

It is convenient to give here the general expressions for transverse forces presented as the functions of displacements:

$$
\begin{aligned}
& Q_{x}=H \delta\left[\frac{\partial^{3} w}{\partial x^{3}}+\frac{\partial^{3} w}{R^{2} \partial x \partial \varphi^{2}}+\frac{1}{R^{3}} \frac{\partial u^{2}(1-\mu)}{2 \partial \varphi^{2}}+\frac{\partial w \mu}{\partial x R^{2}}\right] \\
& Q_{\varphi}=H \delta\left[\frac{\partial^{3} w}{R^{3} \partial \varphi^{3}}+\frac{\partial w}{R^{3} \partial \varphi}+\frac{\partial^{3} w}{R \partial \varphi \partial x^{2}}+\frac{1}{R^{2}} \frac{\partial^{2} u(1-\mu)}{2 \partial \varphi \partial x}\right]
\end{aligned}
$$

As usually expand all parameters in Fourier series along circumferential coordinate. Assume that they can be presented as follows. For displacements:

$$
\begin{gathered}
w(x, \varphi)=w_{n}(x) \cos n \varphi, \\
v(x, \varphi)=v_{n}(x) \sin n \varphi, \\
u(x, \varphi)=u_{n}(x) \cos n \varphi .
\end{gathered}
$$

For forces:

$$
\begin{gathered}
N_{x}(x, \varphi)=N_{x, n}(x) \cos n \varphi, \\
N_{\varphi}(x, \varphi)=N_{\varphi, n}(x) \cos n \varphi, \\
L(x, \varphi)=L_{n}(x) \sin n \varphi .
\end{gathered}
$$

For transverse forces:

$$
\begin{aligned}
& Q_{x}(x, \varphi)=Q_{x, n}(x) \cos n \varphi, \\
& Q_{\varphi}(x, \varphi)=Q_{\varphi, n}(x) \sin n \varphi .
\end{aligned}
$$

For moments:

$$
\begin{aligned}
& M_{x}(x, \varphi)=M_{x, n}(x) \cos n \varphi, \\
& M_{\varphi}(x, \varphi)=M_{\varphi, n}(x) \cos n \varphi, \\
& M_{x \varphi}(x, \varphi)=M_{x \varphi, n}(x) \sin n \varphi .
\end{aligned}
$$

Express all force parameters through the displacements parameters and omit the lower indexes " $n$ ", while implying that all parameters relate to the given value of " $n$ ":

$$
N_{\varphi}=-H\left(n \frac{v}{R}+\frac{w}{R}+\mu \frac{\partial u}{\partial x}\right) \cos n \varphi
$$

$$
\begin{gathered}
N_{x}=-H\left(\frac{\partial u}{\partial x}+\mu n \frac{v}{R}+\mu \frac{w}{R}\right) \cos n \varphi, \\
L=-G h\left(-n \frac{u}{R}+\frac{\partial v}{\partial x}\right) \sin n \varphi, \\
Q_{x}=H \delta\left(\frac{\partial^{3} w}{\partial x^{3}}-\frac{n^{2}-\mu}{R^{2}} \frac{\partial w}{\partial x}-\frac{n^{2}(1-\mu) u}{2 R^{3}}\right) \cos n \varphi \\
Q_{x}=H \delta\left(\frac{\left(n^{3}-n\right) w}{R^{3}}-\frac{n}{R} \frac{\partial^{2} w}{\partial x^{2}}-\frac{n(1-\mu)}{2 R^{2}} \frac{\partial u}{\partial x}\right) \sin n \varphi
\end{gathered}
$$

Note, that each equation of (10) contains either common multiplier $\cos n \varphi$ or $\sin n \varphi$. Furthermore, the choice of parameters in form (6)-(9) provides that all below equations will be proportional only to one trigonometric function. Thus, we will mostly omit them, and retain them only when it will be important for the signs - derivative from cosine give "-" and from sinus gives "+". Substitute (10) into axial equilibrium equation, it gives:

$\left(\frac{d^{2} u}{d x^{2}}+\frac{\mu n}{R} \frac{d v}{d x}+\frac{\mu}{R} \frac{d w}{d x}\right)+n \frac{(1-\mu)}{2 R}\left(-n \frac{u}{R}+\frac{d v}{d x}\right)=0$

Equilibrium equation in circumferential direction is:

$$
\begin{gathered}
\left(n^{2} \frac{v}{R^{2}}+n \frac{w}{R^{2}}+\frac{\mu n}{R} \frac{d u}{d x}\right)-\frac{(1-\mu)}{2}\left(-\frac{n}{R} \frac{d u}{d x}+\frac{d^{2} v}{d x^{2}}\right)+ \\
+\frac{\delta}{R}\left(n^{3} \frac{w}{R^{3}}-n \frac{w}{R^{3}}-\frac{n}{R} \frac{d^{2} w}{d x^{2}}-\frac{n(1-\mu)}{2 R^{2}} \frac{d u}{d x}\right)=0 .
\end{gathered}
$$

Equilibrium in radial direction gives:

$$
\begin{gathered}
H \delta\left(\frac{d^{4} w}{d x^{4}}-\frac{\left(2 n^{2}-\mu\right)}{R^{2}} \frac{d^{2} w}{d x^{2}}+\frac{n^{2}\left(n^{2}-1\right) w}{R^{4}}-\frac{n^{2}(1-\mu)}{R^{3}} \frac{d u}{d x}\right)+ \\
+H\left(n \frac{v}{R^{2}}+\frac{w}{R^{2}}+\frac{\mu}{R} \frac{d u}{d x}\right)=P_{n}(x),
\end{gathered}
$$

where $P_{n}(x)$ is known outer force specified for each value of " $n$ ". In this paper we will consider the most general cases of loading, therefore assume that

$$
P_{n}(x)=2 \cdot \delta(x) \cos n \varphi,
$$

where $\delta(x)$ is Dirac delta function. So, the loading (11d) is symmetrical with respect to the origin of coordinates $x=0$, this allows to formulate corresponding boundary conditions.

\section{Application of the Navier method}

Consider Navier solution in form which satisfies to $x=0$ symmetry. In this case we will seek the unknown functions $w_{n}(x), u_{n}(x), v_{n}(x)$ in (6) in the following form: 


$$
\begin{aligned}
& w_{n}(x)=\sum_{m=0}^{N} A_{m} \cos \left(\frac{m \pi x}{L}\right), \\
& v_{n}(x)=\sum_{m=0}^{N} B_{m} \cos \left(\frac{m \pi x}{L}\right), \\
& v_{n}(x)=\sum_{m=1}^{N} C_{m} \sin \left(\frac{m \pi x}{L}\right),
\end{aligned}
$$

where $L$ is specific length, which should be several times bigger than length of existence of nonzero solution. The choice of this length was discussed in [15], and will be analyzed here too.

Substitution of equations (12) into equilibrium equations (11a), (11b) at given $m$ and $n$ leads to the system of equations, which can be presented as below:

$$
\left\{\begin{array}{l}
f_{1} b_{m}+g_{1} c_{m}=h_{1} \\
f_{2} b_{m}+g_{2} c_{m}=h_{2}
\end{array}\right.
$$

where the following designations are used:

$$
\begin{gathered}
b_{m}=B_{m} / A_{m} ; \quad c_{m}=C_{m} / A_{m} \\
f_{1}=-\frac{m^{2} \pi^{2}}{L^{2}}-\frac{n^{2}(1-\mu)}{2 R^{2}} ; g_{1}=-\frac{m n \pi(1+\mu)}{2 R L} ; \\
f_{2}=\frac{m n \pi}{2 R L}\left(1+\mu-\frac{\delta}{R^{2}}(1-\mu)\right) ; \\
g_{2}=\frac{n^{2}}{R^{2}}+\frac{m^{2} \pi^{2}(1-\mu)}{2 L^{2}} ; \\
h_{1}=\frac{\mu m \pi}{R L}, h_{2}=\frac{n}{R^{2}}\left(1+\frac{\delta}{R^{2}}\left(n^{2}-1+\left(\frac{m \pi R}{L}\right)^{2}\right)\right)
\end{gathered}
$$

Solution of the system (13a) can be presented as:

$$
b_{m}=\frac{g_{2} h_{1}-g_{1} h_{2}}{g_{2} f_{1}-g_{1} f_{2}} ; \quad c_{m}=\frac{f_{1} h_{2}-f_{2} h_{1}}{g_{2} f_{1}-g_{1} f_{2}} .
$$

Now consider equilibrium in radial direction (11c), which we rewrite as:

$$
H \cdot d_{m n} \cdot \cos \left(\frac{m \pi x}{L}\right) A_{m}=P_{n}(x),
$$

where

$$
\begin{gathered}
d_{m n}=\delta \times\left(\frac{m^{4} \pi^{4}}{R^{2} L^{4}}+\frac{\left(2 n^{2}-\mu\right) m^{2} \pi^{2}}{R^{2} L^{2}}+\frac{n^{2}\left(n^{2}-1\right)}{R^{4}}-\right. \\
\left.-\frac{n^{2}(1-\mu) m \pi \cdot b_{m}}{R^{3} L}\right)+\frac{n \cdot c_{m}}{R^{2}}+\frac{1}{R^{2}}+\frac{\mu m \pi \cdot b_{m}}{R L} .
\end{gathered}
$$

The outer loading $P_{n}(x)$ (11d) can easily be expanded into Fourier series, and is:

$$
P_{n}(x)=\frac{1}{L}+\sum_{m=1}^{N} \frac{2}{L} \cos \left(\frac{m \pi x}{L}\right) .
$$

So, substituting (14c) into (14a) and comparing the coefficients at the same cosines, then unknown coefficients $A_{m}$ are derived from:

$$
A_{0}=\frac{1}{L H \cdot d_{0 n}}, \quad A_{m}=\frac{2}{L H \cdot d_{m n}} .
$$

Thus eventually we get the simple formula for each component of the radial displacement expansion:

$$
w_{n}(x)=\frac{1}{L H d_{0 n}}+\sum_{m=1}^{N} \frac{2}{L H d_{m n}} \cos \left(\frac{m \pi x}{L}\right) .
$$

The availability of coefficients allows to get the coefficient (13g) which describe two other components of the displacement field (12b), (12c).

\section{Application of exponential functions in WRM}

Interdependencies between displacements. Take the radial displacement in the following form:

$$
w_{k}(x)=A_{k} e^{-\frac{k x}{L_{1}}} .
$$

Then two other displacements $u_{k}(x), v_{k}(x)$ relate with it through the equilibrium equations (11a) and (11b). Present the above displacements as:

$u_{k}(x)=b(k, n) \cdot w_{k}(x), \quad v_{k}(x)=c(k, n) \cdot w_{k}(x)$.

So, from (11a) and (11b) we have formally the same system (as (13a) in Navier method) of two equations, in which the respective coefficients are:

$$
\begin{gathered}
f_{1}=\frac{k^{2}}{L_{1}^{2}}-\frac{n^{2}(1-\mu)}{2 R^{2}} ; \quad g_{1}=-\frac{k n(1+\mu)}{2 R L_{1}} ; \\
f_{2}=-\frac{k n}{2 R L_{1}}\left(1+\mu-\frac{\delta}{R^{2}}(1-\mu)\right) ; \\
g_{2}=\frac{n^{2}}{R^{2}}-\frac{k^{2}(1-\mu)}{2 L_{1}^{2}}
\end{gathered}
$$

$$
h_{1}=\frac{\mu k}{R L_{1}}, \quad h_{2}=-\frac{n}{R^{2}}\left(1+\frac{\delta}{R^{2}}\left(n^{2}-1-\frac{k^{2} R^{2}}{L_{1}^{2}}\right)\right) \text {. }
$$

The solution of which formally is also given by $(13 \mathrm{~g})$, but we will for completeness rewrite them

$$
b_{m}=\frac{g_{2} h_{1}-g_{1} h_{2}}{g_{2} f_{1}-g_{1} f_{2}} ; \quad c_{m}=\frac{f_{1} h_{2}-f_{2} h_{1}}{g_{2} f_{1}-g_{1} f_{2}} .
$$

Now substitute all components of displacement into equilibrium equation (11c) we will get that left-side, LS, of it can be presented as: 


$$
L S(k, n)=Z(k, n) \cdot A_{k} e^{-\frac{k x}{L_{1}}}
$$

where:

$$
\begin{array}{r}
Z(k, n)=\delta \times\left(\frac{k^{4}}{L_{1}^{4}}+\frac{\left(2 n^{2}-\mu\right) k^{2}}{R^{2} L_{1}^{2}}-\frac{n^{2}(1-\mu) k \cdot b(k, n)}{R^{3} L_{1}}+\right. \\
\left.+\frac{n^{2}\left(n^{2}-1\right)}{R^{4}}\right)+\frac{n \cdot c(k, n)}{R^{2}}+\frac{1}{R^{2}}-\frac{\mu k \cdot b(k, n)}{R L_{1}} .
\end{array}
$$

Basic functions. Introduce the family of new functions $\Gamma_{k}(x)$ and $\Phi_{k}(x)$ :

$$
\Gamma_{k}(x)=\exp \left(-\frac{k x}{L_{1}}\right), \quad 0 \leq x<\infty,
$$

which is well known exponential function and new designation are used only for convenience.

$$
\begin{gathered}
\Phi_{k}(x)=\alpha_{k, 1} \exp \left(-\frac{k x}{L_{1}}\right)+\alpha_{k, 2} \exp \left(-\frac{2 k x}{L_{1}}\right)+ \\
+\alpha_{k, 2} \exp \left(-\frac{3 k x}{L_{1}}\right)+\alpha_{k, 4} \exp \left(-\frac{4 k x}{L_{1}}\right)+ \\
+\alpha_{k, 5} \exp \left(-\frac{5 k x}{L_{1}}\right)=\sum_{i=1}^{5} \alpha_{k, i} \Gamma_{k i}(x), \quad 0 \leq x<\infty .
\end{gathered}
$$

Functions $\Phi_{k}(x)$ will be used as basic functions for construction of displacement component $w_{k}(x)$, i.e:

$$
w_{k}(x)=\Phi_{k}(x)=\sum_{i=1}^{5} \alpha_{k, i} \Gamma_{k i}(x) .
$$

Accounting for relations (16b) and (16g) for functions $u_{k}(x), v_{k}(x)$, they can be presented as:

$$
\begin{aligned}
& u_{k}(x)=\sum_{i=1}^{5} \alpha_{k, i} \cdot b(k i, n) \cdot \Gamma_{k i}(x), \\
& v_{k}(x)=\sum_{i=1}^{5} \alpha_{k, i} \cdot c(k i, n) \cdot \Gamma_{k i}(x) .
\end{aligned}
$$

For determination of unknown coefficients $\alpha_{k, i}$ we need to consider four following conditions of symmetry:

$$
\begin{gathered}
\gamma_{x}(x=0)=w^{\prime}(0)=0, \quad Q_{x}(x=0)=w^{\prime \prime \prime}(0)=0, \\
u(x=0)=0, \quad \frac{d v}{d x}(x=0)=0 .
\end{gathered}
$$

and conditions of decaying at infinity - which were already taken into account by choosing the decaying functions $\Gamma_{k i}(x)$ for their construction:

$$
\lim _{x \rightarrow \infty} w_{k}(x)=0 .
$$

To satisfy boundary conditions (20a) we chose $\alpha_{k, 1}$ to be equal to 1 , and four unknown coefficients $\alpha_{k, i}(i=\overline{2,5})$ are expressed through it. These give four sets of equations for unknown coefficients:

1) From condition $\gamma_{x}(x=0)=0$ we have:

$$
w_{k}^{\prime}(0)=\sum_{i=1}^{5} \alpha_{k, i} \cdot k \cdot i=0 .
$$

2) Condition $u(x=0)=0$ lead to:

$$
u_{k}(0)=\sum_{i=1}^{5} \alpha_{k, i} \cdot b(k i, n)=0 .
$$

3) Zero transverse force gives $u(x=0)=0$ and we have:

$$
w_{k}^{\prime \prime \prime}(0)=\sum_{i=1}^{5} \alpha_{k, i} \cdot(k i)^{3}=0 .
$$

4) Condition for first derivative of circumferential displacement gives:

$$
\frac{d v}{d x}(0)=\sum_{i=1}^{5} \alpha_{k, i} \cdot c(k i, n) \cdot k \cdot i=0 .
$$

Availability of all $\alpha_{k, i}$, according to (19a)-(19c) allows to explicitly get the sets of basic functions $w_{k}(x), u_{k}(x), v_{k}(x)$. The procedure of formal construction of basic function is completed.

It is of interest to see the behavior of the basic functions $\Phi_{k}(x)$. These functions, normalized on theirs values at point $x=0$, are shown on Fig. 2, where only $\Phi_{1}(x)$ is shown in natural scale with respect to abscissa. For all other functions the abscissa was scaled in $\mathrm{k}$ times to compare their general appearance. The following shell dimensions and parameters were used in construction of these functions: $R=40, h=1, \mu=0.3, n=2, L_{I}=500$.

The next most important step of WRM is the determination and minimization of residuals.

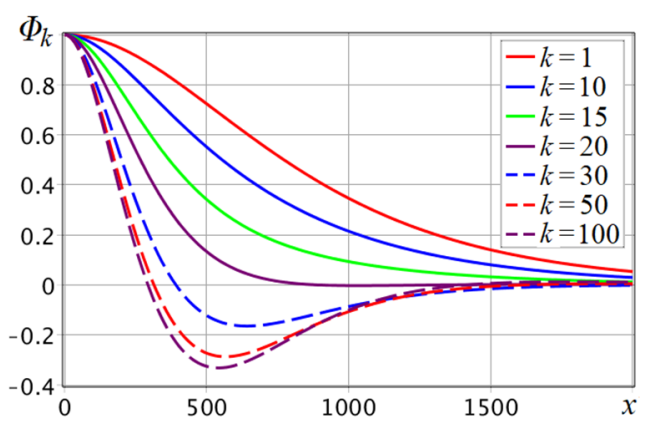

Fig. 2. Basic functions for radial displacement 
WRM for exponential functions. The looking for functions are presented as the series:

$$
\begin{gathered}
w(x)=\sum_{k=1}^{K} \beta_{k} \Phi_{k}(x), \\
u(x)=\sum_{k=1}^{K} \beta_{k} u_{k}(x), \quad v(x)=\sum_{k=1}^{K} \beta_{k} v_{k}(x) .
\end{gathered}
$$

Substitute one set of these functions (at given $k$ ) into equilibrium equation $(11 \mathrm{c})$ we get:

$$
\begin{aligned}
& \beta_{k} \sum_{i=1}^{5} \alpha_{k, i} \Gamma_{k i}(x)\left(\delta \cdot \left[\frac{(k i)^{4}}{L_{1}^{4}}+\frac{\left(2 n^{2}-\mu\right)(k i)^{2}}{R^{2} L_{1}^{2}}+\frac{n^{2}\left(n^{2}-1\right)}{R^{4}}-\right.\right. \\
& \left.\left.-\frac{n^{2}(1-\mu) k i \cdot b(k i, n)}{R^{3} L_{1}}\right]+\frac{n \cdot c(k i, n)}{R^{2}}+\frac{1}{R^{2}}-\frac{\mu k i \cdot b(k i, n)}{R L_{1}}\right)= \\
& =\beta_{k} \sum_{i=1}^{5} \alpha_{k, i} \Gamma_{k i}(x) \cdot Z(k i, n)=\beta_{k} \sum_{i=1}^{5} \xi_{k i} \Gamma_{k i}(x)=\beta_{k} \Omega_{k},(21 \mathrm{c})
\end{aligned}
$$

where $Z(k i, n)$ is given by $(17 \mathrm{~b})$, and coefficients $\xi_{k i}$, and functions $\Omega_{k}$ are introduced for convenience:

$$
\begin{gathered}
\xi_{k i}=\alpha_{k, i} \cdot Z(k i, n), \\
\Omega_{k}=\sum_{i=1}^{5} \xi_{k i} \Gamma_{k i}(x) .
\end{gathered}
$$

So, everything is ready for formulation of the main equation of WRM. Now substituting all functions (21a) and (21b) into equilibrium equation (11c) we get:

$$
\sum_{k=1}^{K} \beta_{k} \sum_{i=1}^{5} \xi_{k i} \Gamma_{k i}(x)=\sum_{k=1}^{K} \beta_{k} \Omega_{k}(x)=P_{n}(x) .
$$

This is the main equation of WRM.

Solution technique by WRM. Keeping in mind the results of paper [15], where the similar task was analyzed and investigated, we note that Galerkin variant of WRM is the most efficient one, especially when concentrated edge force is considered. The reason is that the product of radial force and radial displacement is the applied energy. Thus, multiplication of residuals on the consequent sets of radial displacements, and equating the integrals of their products over the whole length to zero - provides the minimization of residuals between inner and outer energy. So, Galerkin method has clear physical sense.

So, multiply (22a) on functions $\Phi_{m}(x)$ and integrating both sides of it over the whole length, we get:

$$
\int_{0}^{\infty}\left(\sum_{k=1}^{K} \beta_{k} \Omega_{k}(x)\right) \cdot \Phi_{m}(x) d x=\int_{0}^{\infty} P_{n}(x) \cdot \Phi_{m}(x) d x .
$$

It can be formally presented as matrix equation:

$$
X_{k m} \beta_{k}=Y_{m}
$$

where

$$
\begin{gathered}
X_{k m}=\int_{0}^{\infty}\left(\sum_{i=1}^{5} \xi_{k i} \Gamma_{k i}(x)\right) \cdot\left(\sum_{j=1}^{5} \alpha_{m, j} \Gamma_{m j}(x)\right) d x= \\
=\sum_{i=1}^{5} \xi_{k i} \sum_{j=1}^{5} \alpha_{m, j} \frac{L_{1}}{k i+m j}, \\
Y_{m}=\Phi_{m}(x=0)=\sum_{i=1}^{5} \alpha_{m, i} .
\end{gathered}
$$

\section{Examples of calculation}

All numerical results are given for cylindrical shell with $R=40, h=1, \mu=0.3$. The loading case $n=2$ is considered in details, also some results are given for loading distributions $n=6,10,20$ and 60 .

Loading case $\boldsymbol{n}=2$. There are several reasons for detailed analysis of deformation at $n=2$. First one is its wide practical occurrence and significance - say, it exists in zone of conjugation of pipe bend with straight pipe, it relates with initial distortion of form, any local loading, it leads to maximal radial displacements.

Second one - it is most complicated case for application of WRM. The solution has two clearly modes of behavior: the long and short ones [14], both of which should be properly modelled. So, the largest number of basic functions and unknowns are needed for this case, and it was unclear for us at beginning whether the methods would give adequate results.

The results of calculation over the whole range of solution existence are shown on Fig. 3. Here we present the dimensionless values of radial displacements according to the following normalization, obtained from theoretical considerations based on long solution [14]:

$$
W(x)=C \cdot w(x), \quad C=\frac{E h}{P\left(1-\mu^{2}\right)^{3 / 4} \cdot R} \cdot\left(\frac{h}{R}\right)^{3 / 2} .
$$

On example of this graph we explain the general rule of choosing the normalization length parameters ( $L$ in Navier method and $L_{1}$ in WRM). As we see from Fig. 3, $a$, the values of $W(x)$ became small at $x>l_{1}=500$ and solution almost decay at $x \geq l_{0}=1000$. So, the value of $L_{1}$ is chosen to be $L_{1}=l_{1}$, while $L=2 l_{0}=2000$. Note, that these lengths are minimal ones, and we numerically investigated their influence on results. Note, that bigger values of them have required the corresponding increase of number of expansion terms, to give the same accuracy.

So the above numbers are considered by us as the optimal ones.

Returning to the general appearance of graphs, note the following. First, their accuracy was proved by comparison with theoretical approximate results given by [14]. At the whole, the difference between the results by Navier and 
WRM with those by [14] does not exceed $0.5 \%$, which testify about efficiency of all methods. So, graphically all results coincide between themselves, so only theoretical results are shown here. Second, theoretical analysis allows to separate the long and short solutions, thus confirming the existence of both, and on Fig. 3, $b$ in addition to complete (red line) solution is shown only the long (dashed blue line) solution. The maximal contribution of short solution does not exceed $1.75 \%$. Third, visually results for radial displacement by Navier method and WRM coincides with exact values at number of terms $N \geq 250$ for Navier method and $K \geq 20$ for WRM.

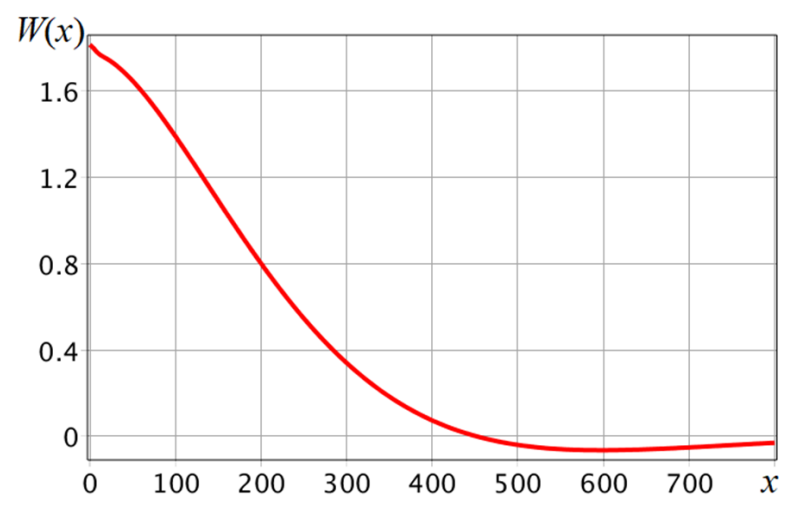

$a$

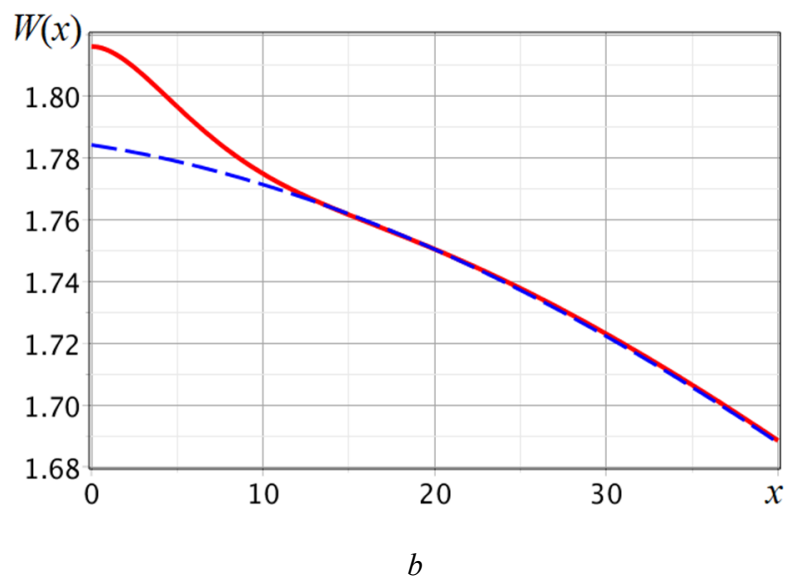

Fig. 3. Radial displacement, $n=2,(a)$ - general view, $(b)$ - detailed picture near the force application point

It is of interest to explore in details the contribution of number of terms in corresponding expansions on the accuracy. This is illustrated by Fig. 4.

At $K=10$ WRM gives better accuracy that Navier method at $N=100$.

In practice, the more important are bending moments. Their theoretical values [14] as well as calculated by Navier method and our variant of WRM are shown on Fig. 5. The complete dependance of bending moments $M_{x}(x)$ and $M_{\varphi}(x)$ over the whole region is shown on
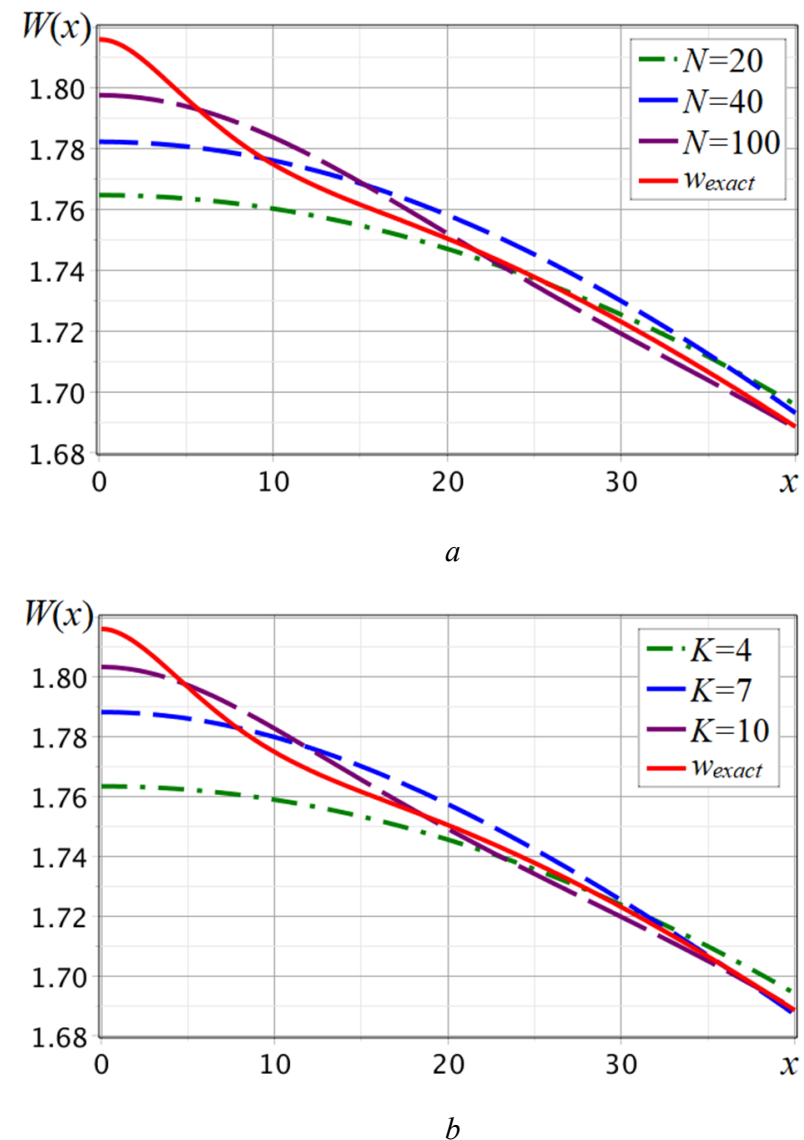

Fig. 4. Radial displacement with respect the number of terms in expansion, $n=2$ : $(a)$ Navier method; (b) WRM

Fig. 5, $a$, here the discrepancies with approximate analytical solution also does not exceed $0.5 \%$. Generally, their range of noticeable existence is slightly smaller than for displacements. The detailed picture (in vicinity of origin) of the moment distribution is shown on Fig. 5, $b$. Here the contribution of short solution is more salient than for displacements. The full solution is shown by solid line, while the long one - by the dashed lines. As we see, the short solution exhibits itself within $30-40 \mathrm{~mm}$ from the beginning. The contribution of short solution to $M_{\phi}(x)$ is explained by existence of Poisson's ratio in physical expression (2c). Note, that visual coincidence of analytical and Navier and WRM results begin from $K \geq 50$ and $N \geq 4000$.

The detailed analysis of influence of number of terms on accuracies is shown in Table 1. Evidently that both Navier and WRM require much lesser term for prediction of accurate values for displacements than for moments. So, for 500 terms for Navier method and 20 terms in WRM are enough to provide $0.2 \%$ accuracy. As to bending moments - the number of terms should be much bigger. Here the short solution, which is small for displacements, gives a big contribution to bending moments and for its modelling we need to have the terms with large value of $m$ - for Navier method and of $k$ - for WRM. For example, 

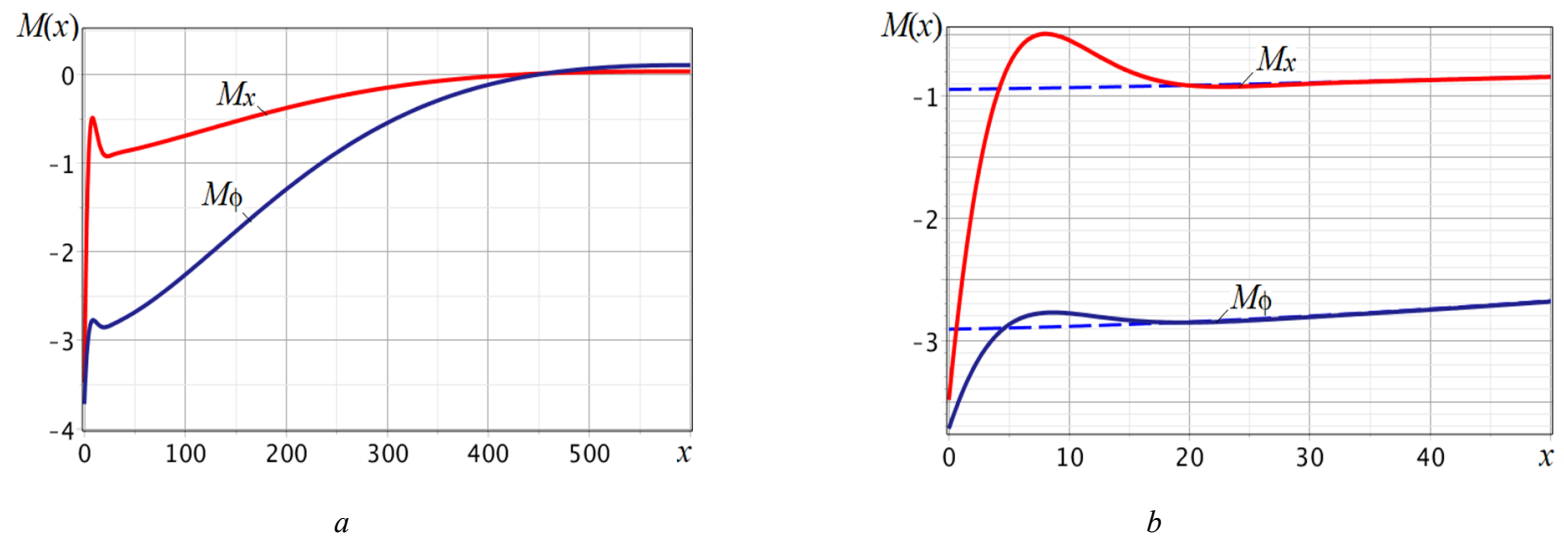

Fig. 5. Bending moments, $n=2,(a)$ - general view, $(b)$ - detailed picture near the force application point

Table 1. Maximum of radial displacements and moments at different numbers of terms in Navier method and WRM

\begin{tabular}{|c|c|c|c|c|c|c|c|}
\hline \multicolumn{4}{|c|}{ Navier method } & \multicolumn{4}{|c|}{ Exponential functions based WRM } \\
\hline $\begin{array}{c}N, \text { numbers } \\
\text { of terms }\end{array}$ & $W(0)$ & $|M x(0)|$ & $|M \varphi(0)|$ & $\begin{array}{c}K, \text { numbers } \\
\text { of terms }\end{array}$ & $W(0)$ & $|M x(0)|$ & $|M \varphi(0)|$ \\
\hline \multicolumn{4}{|c|}{$n=2, L=2000$} & \multicolumn{4}{|c|}{$n=2, L_{1}=500$} \\
\hline 20 & 1.78095 & 0.93468 & 2.88088 & 5 & 1.77726 & 0.96008 & 2.90622 \\
\hline 100 & 1.79789 & 1.13471 & 2.98900 & 10 & 1.80343 & 1.33185 & 3.05630 \\
\hline 500 & 1.81569 & 2.68547 & 3.48045 & 20 & 1.81608 & 3.04185 & 3.58794 \\
\hline 1000 & 1.81613 & 3.08580 & 3.60119 & 50 & 1.81619 & 3.42964 & 3.70443 \\
\hline 8000 & 1.81619 & 3.43990 & 3.70752 & 100 & 1.81619 & 3.46914 & 3.71629 \\
\hline 32000 & 1.81619 & 3.47789 & 3.71892 & 150 & 1.81619 & 3.47379 & 3.71768 \\
\hline 64000 & 1.81619 & 3.48422 & 3.72082 & 200 & 1.81619 & 3.48515 & 3.72109 \\
\hline 512000 & 1.81619 & 3.48977 & 3.72248 & 250 & 1.81619 & 3.48648 & 3.72149 \\
\hline \multicolumn{4}{|c|}{$n=6, L=250$} & \multicolumn{4}{|c|}{$n=6, L_{1}=80$} \\
\hline 20 & 0.13428 & 1.57720 & 2.78095 & 5 & 0.13995 & 2.20921 & 3.06823 \\
\hline 100 & 0.14240 & 2.98943 & 3.34417 & 10 & 0.14250 & 3.22670 & 3.41706 \\
\hline 500 & 0.14251 & 3.38809 & 3.46581 & 20 & 0.14252 & 3.42700 & 3.47749 \\
\hline 1000 & 0.14252 & 3.43864 & 3.48099 & 50 & 0.14252 & 3.47921 & 3.49316 \\
\hline 8000 & 0.14252 & 3.48294 & 3.49428 & 100 & 0.14252 & 3.48589 & 3.49517 \\
\hline 16000 & 0.14252 & 3.48611 & 3.49523 & 150 & 0.14252 & 3.48779 & 3.49574 \\
\hline 64000 & 0.14252 & 3.48848 & 3.49594 & 200 & 0.14252 & 3.48858 & 3.49597 \\
\hline \multicolumn{4}{|c|}{$n=10, L=50$} & \multicolumn{4}{|c|}{$n=10, L_{1}=15$} \\
\hline 20 & 0.036052 & 2.02626 & 2.36055 & 5 & 0.036148 & 2.26600 & 2.43714 \\
\hline 50 & 0.036155 & 2.31007 & 2.45065 & 10 & 0.036162 & 2.44069 & 2.49018 \\
\hline 500 & 0.036162 & 2.48975 & 2.50493 & 20 & 0.036162 & 2.49204 & 2.50562 \\
\hline 1000 & 0.036162 & 2.49987 & 2.50797 & 50 & 0.036162 & 2.50677 & 2.51003 \\
\hline 8000 & 0.036162 & 2.50873 & 2.51062 & 100 & 0.036162 & 2.50874 & 2.51063 \\
\hline 64000 & 0.036162 & 2.50984 & 2.51096 & 200 & 0.036162 & 2.50978 & 2.51094 \\
\hline \multicolumn{4}{|c|}{$n=20, L=25$} & \multicolumn{4}{|c|}{$n=20, L_{1}=8$} \\
\hline 20 & 0.0046238 & 1.05594 & 1.22273 & 5 & 0.0046339 & 1.23083 & 1.27717 \\
\hline 100 & 0.0046375 & 1.24754 & 1.28288 & 10 & 0.0046362 & 1.25941 & 1.28621 \\
\hline 1000 & 0.0046376 & 1.29284 & 1.29650 & 20 & 0.0046376 & 1.28820 & 1.29510 \\
\hline 8000 & 0.0046376 & 1.29727 & 1.29783 & 50 & 0.0046376 & 1.29741 & 1.29787 \\
\hline 64000 & 0.0046376 & 1.29782 & 1.29799 & 100 & 0.0046376 & 1.29769 & 1.29795 \\
\hline \multicolumn{4}{|c|}{$n=60, L=8$} & \multicolumn{4}{|c|}{$n=60, L_{1}=3$} \\
\hline 20 & 0.00017120 & 0.35581 & 0.40931 & 5 & 0.00017130 & 0.41874 & 0.42836 \\
\hline 100 & 0.00017165 & 0.41725 & 0.42853 & 10 & 0.00017163 & 0.41987 & 0.42928 \\
\hline 1000 & 0.00017165 & 0.43175 & 0.43289 & 20 & 0.00017165 & 0.43122 & 0.43273 \\
\hline 8000 & 0.00017165 & 0.43316 & 0.43331 & 50 & 0.00017165 & 0.43299 & 0.43325 \\
\hline 64000 & 0.00017165 & 0.43334 & 0.43336 & 80 & 0.00017165 & 0.43336 & 0.43337 \\
\hline
\end{tabular}


50 terms in WRM give 2\% accuracy, while 1000 Navier terms give only $10 \%$ accuracy; $100 \mathrm{WRM}$ terms $-0.5 \%$ and 32000 Navier terms $-0.3 \%$. At the whole WRM requires for this task approximately in 2 order lesser terms for similar accuracy.

Graphically the influence of number of terms on calculated moments are shown on Fig. 6. Thus, on Fig. 6, a the results by Navier method are presented. We can see that for $N>1000$ there is a visual correspondence of calculated results with exact ones, the divergence exists only in vicinity of the origin. For WRM, the results visually coincide starting from $K>20$, of course with exception of the point of origin.
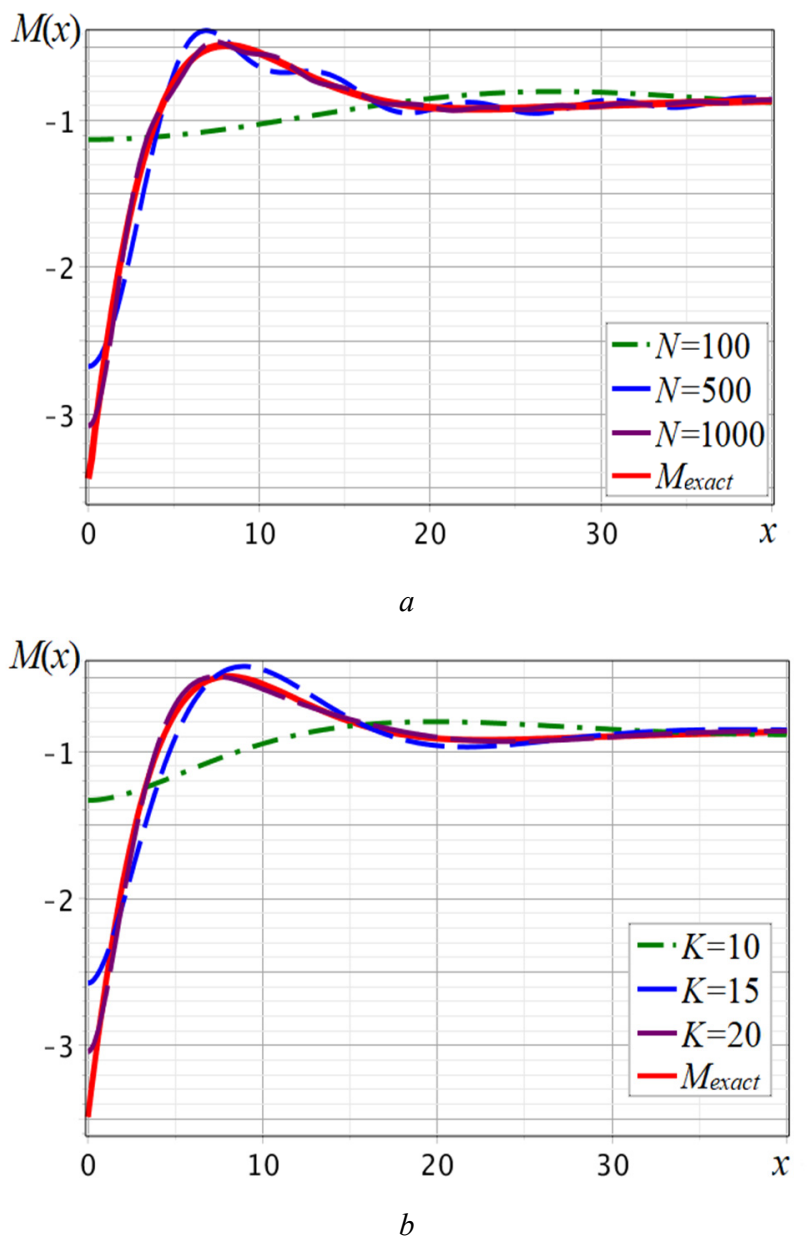

Fig. 6. Bending moments $M_{x}, n=2$, with respect to the number of terms in expansion: $(a)$ Navier method; (b) WRM

Loading case $\boldsymbol{n} \geq 6$. The similar behavior as for $n=2$ pertains for small values of $\mathrm{n}=3,4,5$ and also have two visually distinct range of influence - short and long solutions. Yet with increase of value of $n-$ the shorter solution become more longer and vice versa. The value $n=6 \approx \sqrt{R / h}=\sqrt{40}$ is considered here as a crucial one, where the basic hypothesis of both solutions may became violated. So, this case $n=6$ is very attractive, and it can be analyzed here from two points of view - a) as long and short solution, b) and as a plate like solution. The later was mentioned in work [11], and will be considered here as well.

Detailed distribution of radial displacement is shown on Fig. 7, a. Shown here is a theoretical short and long solution, where dashed line is a long solution and a solid red line - sum of short and long. The Navier and WRM results are almost coincide with it, so we do not show them here. The same is related to the distribution of bending moments, Fig. $7, b$.
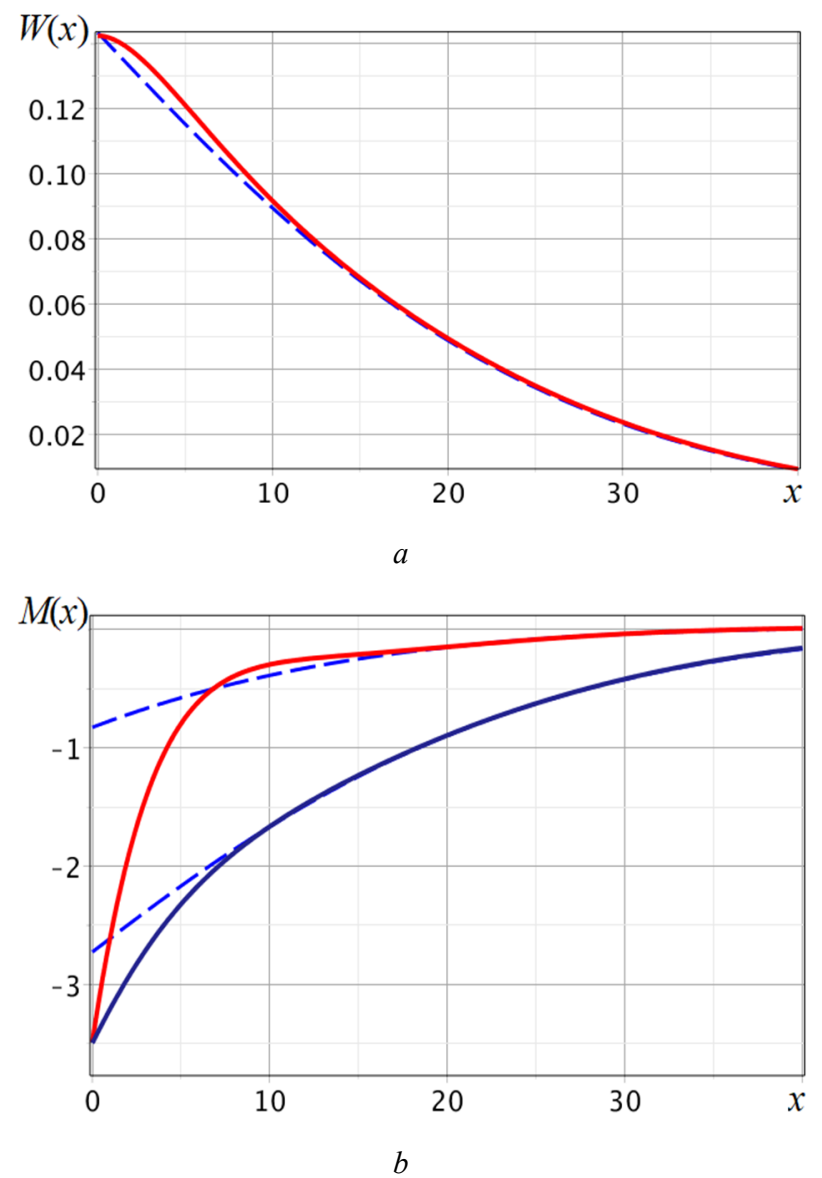

Fig. 7. Detailed picture near the force application point of radial displacement $(a)$ and bending moments $(b)$, at $n=6$

Note that the difference between the approximate and WRM results reach up to $3 \%$, all divergences take place only near the point $x=0$. In other points the coincidence is much better.

The influence of number of terms on accuracy is demonstrated on Fig. 8. The increase of number of terms in Navier method up to $N=100$ give very good results anywhere except the point of origin, where the error can reach up to $16 \%$. As to exponential WRM the number of terms $K=10$ provides the fine accuracy anywhere but for point $x=0$, where error is equal to $8 \%$. Nevertheless, the convergence to the correct result at $x=0$ go slowly with increase of number of terms, and perfect accuracy (less than $0.1 \%$ is attained at $K=100$ for WRM, and $N=16000$ for Navier method), see Table 1 . This is very common problem 
in analysis of concentrated forces [16], where correct evaluation of bending moment requires a large number of terms. Nevertheless, we can note that exponential functions are much more suitable for modelling the concentrated forces and requires the several orders lesser terms.
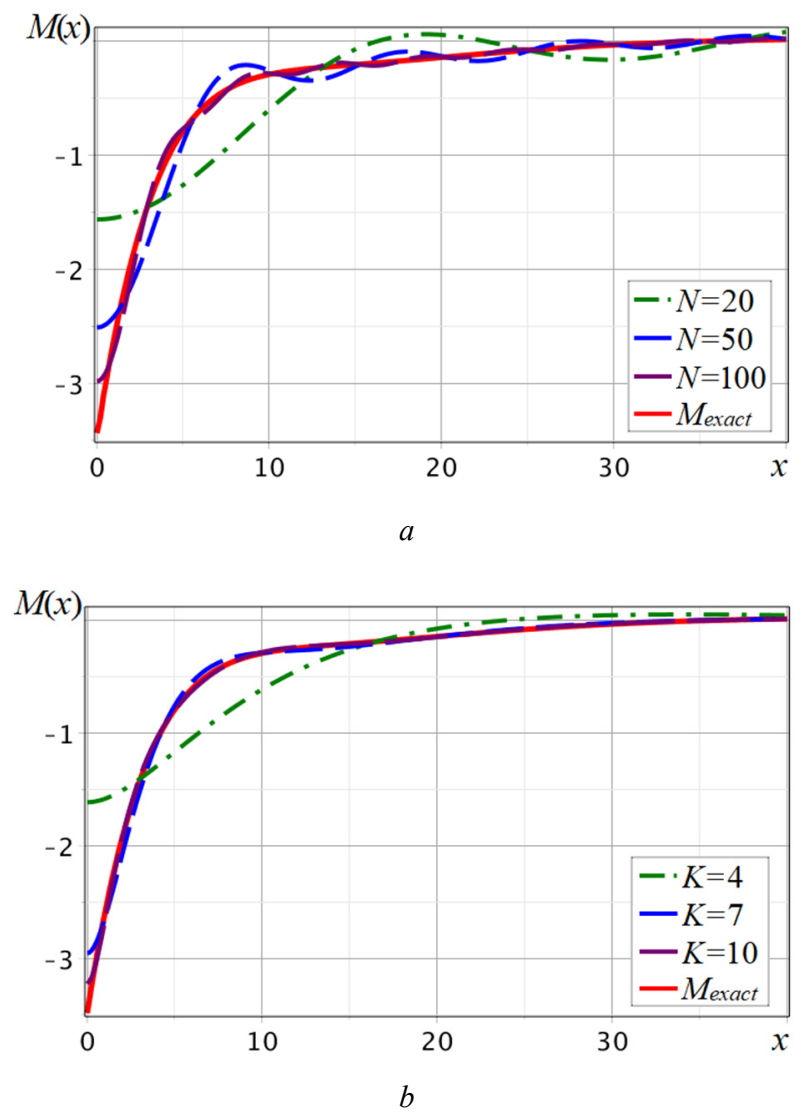

Fig. 8. Bending moments $M_{x}, n=6$, with respect to the number of terms in expansion: $(a)$ Navier method; (b) WRM

Now consider so-called plate solution [11] for cylindrical shell. It takes place when $n^{4} h^{2} / 12 R^{2}>1$, and $n \geq 10$ is near to this border. The plate solution is characterized by following conditions of self similarity. If the loading is given in form (11d), then all graphs for all parameters are resemble each other. Omitting theoretical explanation, note that radial displacements and bending moments can be presented as function from dimensionless distance $x^{*}=x / \lambda_{n}$, where $\lambda_{n}=n / R$ in the following form:

$$
w_{n}(x)=\tilde{W}\left(x^{*}\right) / C \lambda_{n}^{3} ; \quad M_{x, n}(x)=\tilde{M}_{x}\left(x^{*}\right) / \lambda_{n},
$$

where the functions $\tilde{W}\left(x^{*}\right)$ and $\tilde{M}_{x}\left(x^{*}\right)$ at $n \geq 10$ almost do not depend on number $n$ and follows from theoretical solution. These theoretical finding are confirmed by results of Table 1. As we can see from it:

- amplitudes of values of $W_{n}(x=0)$ are proportional to $(R / n)^{3}$ and values $M_{x, n}(x=0)-$ to $R / n$;
- solution domain is proportional to $R / n$, and we take for construction of trial function the correspondent values of $L$ and $L_{1}$.

To show this more evidently, build the graphical dependences of these artificial functions $\tilde{W}\left(x^{*}\right)$ and $\tilde{M}_{x}\left(x^{*}\right)$, which are constructed from real $w_{n}(x)$ and $M_{x, n}(x)$. The latter are numerically calculated by Navier method and WRM and reduced to above functions according to dependances (24). These graphs for $\widetilde{W}\left(x^{*}\right)$ are given on Fig. 9, a, and for $\tilde{M}_{x}\left(x^{*}\right)-$ on Fig. 9, $b$. Evidently, that at $n=6$ and $n=8$ the solutions are still differ from "plate" solution, but at $n \geq 10$ all other graphs coincide between themselves, thus confirming the existence of universal "plate" solution.
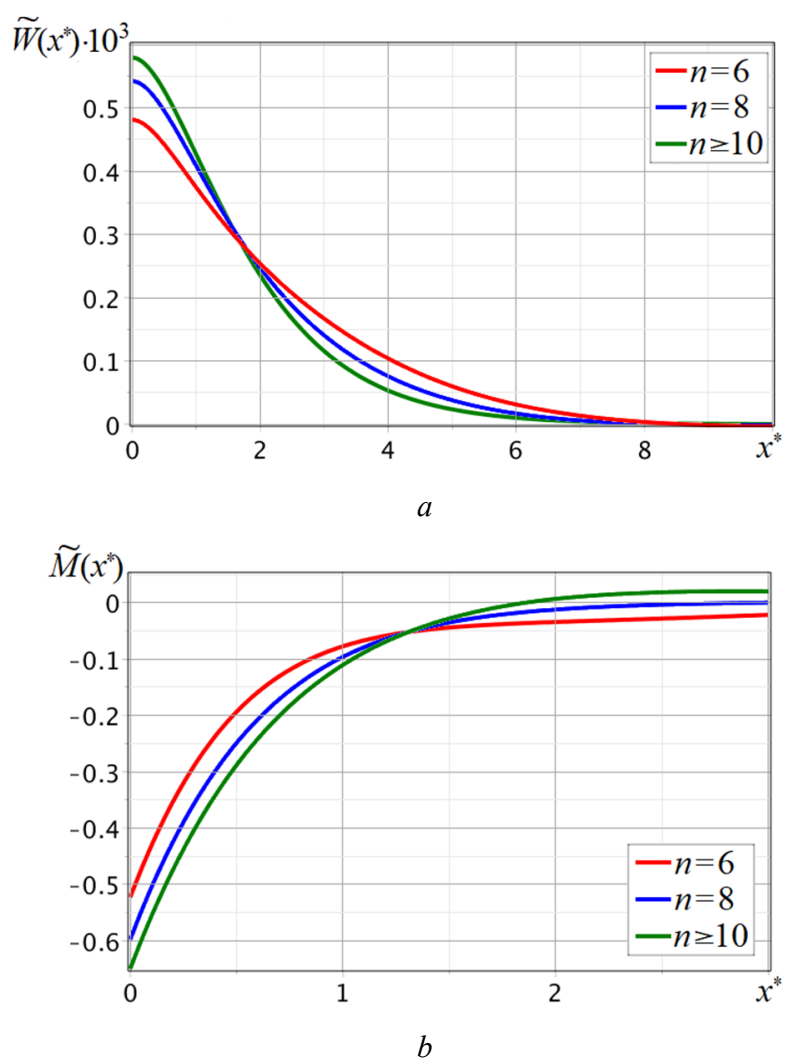

Fig. 9. Radial displacements ( $a$ ) and bending moments $(b)$ for larger values of $n$

As to accuracy and required number of terms, they can be established from results of Table 1. Generally, WRM requires on two order lesser terms to provide the "perfect" accuracy than Navier method, and for "plate" solution 5 terms can provide quite satisfactory results.

\section{Conclusions}

This paper is devoted to the interesting classical problem of cylinder under concentrated radial force and in 
first time establish correct (at least, in engineering sense) values of stresses and displacements for particular loading (11d). Furthermore, it gives a universal instrument, we mean exponential function in WRM, which can readily be applicable by engineers to other practical and complicated problems. Three methods are discussed in this paper: our former results for long and short solutions, Navier method and exponential functions application in WRM.

1) Detailed analysis of displacements and moments at $n=2$ for loading (11d) for all three methods have demonstrated their perfect accuracies. The availability of two distinct separate mode of solution behavior - short range and long range ones, generally do not prevent finding the correct results by Navier method and WRM. Nevertheless, this required too many terms in expansions. So, analytical approach can be considered as a best choice treatment of ovalization-like deformation.

2) Navier method is the simplest method to implement numerically. It uses the orthogonal functions, which simplify the process of minimization of residual. Neverthe- less, its success is explained by simple boundary conditions, which allows to apply the corresponding expansion. Navier method has very restricted perspectives for further application to finite bodies with different loading and boundary conditions. Besides, it requires sometimes prohibitively large number of terms.

3) Application of exponential function in WRM is a very instrumental for various practical tasks. Generally, their application required in two order lesser terms of expansion as compared with Navier method. These functions are very easy to handler with in differentiation and integration and relatively easy allows to satisfy all boundary conditions. This opens a wide perspective of their future application.

4) For concrete task of cylindrical shell with $R / h=40$, the approximate analytical short and long solutions is still able to give correct behavior up to $n=6$, which is $\approx \sqrt{R / h}$, where the maximal difference reach $3 \%$. As to larger $n$, starting from $n=10$, all solutions are self similar and can be considered as universal "plate" type solutions.

\section{References}

[1] D. Ren and K.-C. Fu, "Solutions of complete circular cylindrical shell under concentrated loads", Journal of engineering mechanics, vol. 127, no. 3, pp. 248-253, 2001. doi: 10.1061/(ASCE)0733-9399(2001)127:3(248)

[2] S.W. Yuan, "Thin cylindrical shells subjected to concentrated loads", Quarterly of Applied Mathematics, vol. 4, no. 1, pp. 1326, 1946. doi.org/10.1090/qam/16031

[3] L.S.D. Morley, "The thin-walled circular cylinder subjected to concentrated radial loads", The Quarterly Journal of Mechanics and Applied Mathematics, vol. 13 (1), pp. 24-37, 1960. doi: 10.1093/qjmam/13.1.24

[4] S. Lukasiewicz, Local loads in plates and shells, Warszawa: PWN-Polish Scientific Publishers, 1979.

[5] P.P. Bijlaard, "Stresses from radial loads in cylindrical pressure vessels", Welding Journal, vol. 33 (12), pp. 615-623, 1954.

[6] K. Mizoguchi, H. Shiota and K. Shirakawa, "Deformation and stress in a cylindrical shell under concentrated loading: 1 st report, Radial loading”, Bulletin of JSME, vol. 11 (45), pp. 393-403, 1968. doi.org/10.1299/jsme1958.11.393

[7] V.Z. Vlasov, General theory of shells and its applications in engineering, Washington: National Aeronautics and Space Administration, 1964.

[8] B.V. Nerubailo, "Radial displacement of a long cylindrical shell subjected to radial concentrated forces", Soviet Applied Mechanics, vol. 10, pp. 1128-1131, 1974. doi: 10.1007/BF00882358

[9] V.P. Ol'shanskii, "Maximal deflection of cylindrical shells under a concentrated force", Strength of Materials, vol. 22, pp. 15231526, 1990. doi: 10.1007/BF00767243

[10] V.P. Shevchenko, "Fundamental-solution methods in stress-concentration problems for thin elastic shells", International Applied Mechanics, vol. 43, pp. 707-725, 2007. doi: 10.1007/s10778-007-0070-2

[11] C.R. Calladine, Theory of shell structures. Cambridge University Press, 1983. doi: 10.1017/CBO9780511624278

[12] I. Orynyak, A. Bogdan and I. Selivestrova, "The application of long and short cylindrical shell solutions for stress and flexibility determination in a single mitred bend", Proceedings of the ASME 2016 Pressure Vessels and Piping Conference, 2016. doi: 10.1115/PVP2016-63598

[13] I. Orynyak and A. Oryniak, "Efficient solution for cylindrical shell based on short and long (enhanced Vlasov's) solutions on example of concentrated radial force", Proceedings of the ASME 2018 Pressure Vessels and Piping Conference, 2018. doi: 10.1115/PVP2018-85032

[14] A. Oryniak and I. Orynyak, "Application of short and long (enhanced Vlasov's) solutions for cylindrical shell on example of concentrated radial force”, J. Pressure Vessel Technol., vol. 143 (1): 014501, 2021. doi: 10.1115/1.4047828

[15] I.V. Orynyak and Y.P. Bai, "Application of exponential functions in weighted residuals method in structural mechanics. Part 1: axisymmetrical shell problem”, Mechanics and Advanced Technologies, no. 3 (90), pp. 19-28, 2020. doi: 10.20535/25211943.2020.0.209618

[16] S.P. Timoshenko, S. Woinowsky-Krieger, Theory of plates and shells. $2^{\text {nd }}$ ed. New York, USA: McGraw - Hill, 1959. 


\title{
Застосування експоненціальних функцій в методі зважених нев'язок в структурній механіці на прикладі осесиметричної задачі оболонки під дісю зосереджених сил
}

\begin{abstract}
І.В. Ориняк, Ю.П. Бай, А.В. Григоренко
Анотація. Рімення для ичиліндричної оболонки під дією зосередженої сили є однією з основних проблем, яка дозволяє розглянути багато інших випадків навантаження та геометрії. Існуючі рімення базувались на спрощених припущеннях, $і$ діапазони їх точності досі залишаються невідомими. Загальна ідея полягає в розкладі їх у ряди Фур'є за окружною координатою. Це зводить задачу до диферениійного рівняння 8-го порядку відносно осьової координати. Проте знаходження відповідних 8 власних функцій та точне співвідномення 8 констант інтегрування з граничними умовами все ще перевищують можливості аналітичної обробки. У иій роботі ми застосовуємо затухаючі експоненційні функиії у галер-кінській версії методу зважених нев 'язок (МЗН) до вказаного вище рівняння 8-го порядку. Отже, ми будуємо набори базисних функцій, кожна з яких задовольняє граничним умовам, а також окружному і осьовому рівнянням рівноваги. Останні дають взаємозалежності між коефіцієнтами окружних та осьових переміщень з радіальними. Що стосується радіальної рівноваги, то вона задовольняється лише приблизно за рахунок мінімізаиї нев'язок. Подібним чином ми розробили методику застосування Нав'є-подібної версії МЗН. Результати та особливості застосування МЗН детально обговорюються для концентрованого навантаження виду $\cos 2 \varphi$, ще методологічно є найскладнішим випадком, оскільки воно охоплює найбільшу відстань над циліндром. Рішення для нього чітко демонструє два типи поведінки - довгохвильову та короткохвильову, аналітична методика їх побудови була розроблена першим автором в іншій роботі, і тут успішно порівняна. Цей приклад демонструє відмінну точність двох напіваналітичних методів, Нав'є та МЗН. Було показано, щео метод Нав'є, хоч і є простішим у реалізації, все ж вимагає набагато більше доданків (принаймні, на два порядки), ніж метод зважених нев'язок з використанням експоненційних функцій.
\end{abstract}

Ключові слова: нескінченна иџліндрична оболонка, концентрована радіальна сила, метод Галеркіна, метод Нав'є, точність, кількість членів, короткі та довгі розв'язки.

\section{Применение экспоненциальных функций в методе взвешенных невязок в структурной механике на примере осесимметричной задачи оболочки под действием сосредоточенных сил}

\section{И. В. Орыняк, Ю. П. Бай, А.В. Григоренко}

Аннотация. Решение для ицилинрической оболочки под действием сосредоточенной силь является одной из фундаментальных проблем, которая позволяет рассматривать многие другие случаи нагружения и геометрии. Существуюшие решения были основаны на упрощенных предположениях, и диапазоны их точности до сих пор остаются неизвестными. Общей идеей является разложение их в ряд Фурье по окружной координате. Это сводит задачу к дифференциальному уравнению 8-го порядка по осевой координате. Тем не менее, поиск соответствующих 8 собственных функиий и точной связи 8 констант интегрирования с граничными условиями все ещче находится за пределами возможностей аналитического решения. В этой статье мы применяем затухаюшце экспоненциальные функции в галеркинской версии метода взвешенных невязок (МВН) к указанному уравнению 8-го порядка. Наборы базисных функций строятся так, что каждая из них удовлетворяет граничнылм условиям, а также уравнениям осевого и окружного равновесия. Последние дают взаимозависимости коэффициентов окружных и осевых перемещений с радиальныли. Что касается радиального равновесия, то оно достигается только приближенно за счет минимизации невязок. Аналогичным образом мы разработали методику применения Навье-подобной версии МВН. Подробно обсуждаются результаты и особенности применения МВН для сосредоточенной нагрузки вида сол $2 \varphi$, которая методически является наиболее сложным случаем, поскольку охватьвает наибольшее расстояние по ичилидру. Решение для него явно демонстрирует два типа поведения - длинноволновое и коротковолновое, аналитическая методика их построения была разработана первым автором в другой работе, и здесь было успешно проведено сравнение. Этот пример демонстрирует превосходную точность двух полуаналитических методов, Навье и МвН. Показано, что метод Навье, будучи более простым в реализации, все же требует гораздо больше слагаемых (по крайней мере, на два порядка), чем метод взвешенных невязок с использованием экспоненциильных функций.

Ключевые слова: бесконечная цүилндрическая оболочка, сосредоточенная радиальная сила, метод Галеркина, метод Навье, точность, количество членов, короткие и длинные решения. 